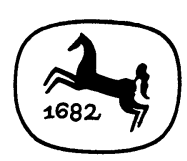

Arthur Henkel · Kleine Schriften 2 - Der Zeiten Bildersaal 
Arthur Henkel

\section{Der Zeiten Bildersaal}

Studien und Vorträge

J.B. Metzlersche Verlagsbuchhandlung Stuttgart 
CIP-Kurztitelaufnahme der Deutschen Bibliothek

\section{Henkel, Arthur:}

Kleine Schriften / Arthur Henkel. - Stuttgart:

Metzler

NE: Henkel, Arthur: [Sammlung]

2. $\rightarrow$ Henkel, Arthur: Der Zeiten Bildersaal

Henkel, Arthur:

Der Zeiten Bildersaal: Studien u. Vorträge / Arthur Henkel. - Stuttgart: Metzler, 1983.

(Kleine Schriften / Arthur Henkel; 2)

ISBN 978-3-476-00546-5

ISBN 978-3-476-00546-5

ISBN 978-3-476-03187-7 (eBook)

DOI $10.1007 / 978-3-476-03187-7$

(C) Springer-Verlag GmbH Deutschland 1983

Ursprünglich erschienen bei J.B. Metzlersche Verlagsbuchhandlung und Carl Ernst Poeschel Verlag GmbH in Stuttgart 1983 


\section{Inhalt}

In Mortem Simii Heidelbergensis 9

Zu einem Epikedium des Jacobus Micyllus

Die geheimnisvolle Welt der Embleme 25

Ein Vortrag

Lessings Traum von einem deutschen Drama 55

Ein Vortrag

In telonio sedens $\quad 81$

J. G. Hamann in den Jahren 1778-1782

Was ist eigentlich romantisch? 93

Ein Vortrag

Erwägungen zur Szene II,5 in Kleists Amphitryon 107

Antikritischer Epilog 125

Zur Frage nach dem Sinn von Kleists Amphitryon

Traum und Gesetz in Kleists Prinz Friedrich von Homburg

Ein Vortrag

Versuch über Des Knaben Wunderhorn 157

Beim Wiederlesen Gottfried Kellers

I Romeo und Julia auf dem Dorfe 173

II Das Tanzlegendchen 183

Kafka und die Vaterwelt 199

Beim Wiederlesen von Hofmannsthals

Die Frau obne Schatten notiert 219

Rilke zu den Liebesgedichten Ricarda Huchs 223

Nachweise und Anmerkungen 239 


\section{Statt eines Vorwortes}

(zugleich als Motto:)

\section{Was in der Zeiten Bildersaal \\ Jemals ist trefflich gewesen, Das wird immer einer einmal Wieder auffrischen und lesen.}

Goethe: Sprichwörtlich

Heidelberg, 10. Juni 1983 